$5-1-2012$

\title{
Human Sperm DNA Oxidation, Motility and Viability in The Presence of I-Carnitine During in Vitro Incubation and Centrifugation
}

\author{
S. Banihani \\ Cleveland State University \\ R. Sharma \\ Cleveland Clinic
}

Mekki Bayachou

Cleveland State University, M.BAYACHOU@csuohio.edu

Eollow this and additional works at: https://engagedscholarship.csuohio.edu/scichem_facpub E. Sabanegh

vedandf Clieichemistry Commons

\section{How does access to this work benefit you? Let us know!}

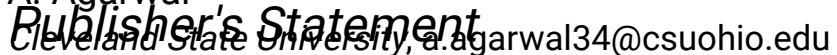

This is the accepted version of the following article: Banihani, S.; Sharma, R.; Bayachou, M.;

Sabanegh, E.; Agarwal, A. Human sperm DNA oxidation, motility and viability in the presence of I-carnitine during in vitro incubation and centrifugation. Andrologia 2012, 44, 505-512. , which has been published in final form at: http://onlinelibrary.wiley.com/doi/10.1111/ j.1439-0272.2011.01216.x/abstract

\section{Recommended Citation}

Banihani, S.; Sharma, R.; Bayachou, Mekki; Sabanegh, E.; and Agarwal, A., "Human Sperm DNA Oxidation, Motility and Viability in The Presence of I-Carnitine During in Vitro Incubation and Centrifugation" (2012). Chemistry Faculty Publications. 314.

https://engagedscholarship.csuohio.edu/scichem_facpub/314

This Article is brought to you for free and open access by the Chemistry Department at EngagedScholarship@CSU. It has been accepted for inclusion in Chemistry Faculty Publications by an authorized administrator of EngagedScholarship@CSU. For more information, please contact library.es@csuohio.edu. 


\title{
Human sperm DNA oxidation, motility and viability in the presence of L-carnitine during in vitro incubation and centrifugation
}

\author{
S. Banihani , R. Sharma , M. Bayachou , E. Sabanegh \& A. Agarwal
}

Keywords

Antioxidants DNA oxidation human

sperm L carnitine motility viability

\begin{abstract}
Summary
In vitro incubation and centrifugation is known to decrease human sperm quality. In the human body, besides its antioxidant effects, L carnitine (LC) facilitates the transport of activated fatty acids from the cytosol to the mito chondrial matrix. In this study, we investigated the effect of LC on human sperm motility, viability and DNA oxidation after incubation and centrifuga tion, following the sperm preparation protocols of assisted reproduction. Nor mozoospermic semen samples $(n=55)$ were analysed according to the World Health Organization (WHO) guidelines. LC concentrations that are not toxic to spermatozoa as determined by sperm motility and viability were standar dised after 2 and $4 \mathrm{~h}$ of incubation at $37^{\circ} \mathrm{C}$. Semen samples to which the opti mal LC concentrations were added were also centrifuged for $20 \mathrm{~min}$ at $300 \mathrm{~g}$ and analysed for sperm motility, viability and DNA oxidation. Sperm motility was improved at $0.5 \mathrm{mg} \mathrm{ml}^{1}$ LC after incubation and centrifugation with $5 \times 10^{6}$ sperm $\mathrm{ml}^{1}$. Higher concentration of LC $\left(50 \mathrm{mg} \mathrm{ml}^{1}\right)$ significantly decreased sperm motility and viability. LC did not alter the baseline of sperm DNA oxidation during both incubation and centrifugation. In conclusion, LC may enhance sperm motility following incubation and centrifugation, while it might not affect sperm viability and DNA oxidation.
\end{abstract}

\section{Introduction}

Infertility affects one in seven couples who are trying to conceive (Lamb \& Lipshultz, 2000; Brugh \& Lipshultz, 2004). Decreased semen quality, a measure of the ability of semen to achieve fertilisation, is a primary cause of male infertility. Usually, poor semen quality is character ised by low sperm motility and viability. Assisted repro ductive techniques (ART) such as intra uterine insemination and in vitro fertilisation with or without intracytoplasmic sperm injection are the most successful therapeutic means for male factor infertility.

Sperm preparation protocols used in ART involve sperm incubation and centrifugation. It was reported that sperm motility and viability decrease over time after ejac ulation (Singer et al., 1980). Further, a rapid decline in motility was noted after incubating periods lasting more than $4 \mathrm{~h}$ at $37^{\circ} \mathrm{C}$ (Jeulin et al., 1982). A recent report suggested that different centrifugation protocols adversely affect sperm recovery (Matas et al., 2007). Increased cen trifugation speeds $(>500 \mathrm{~g})$ significantly increases the number of dead spermatozoa (Makler \& Jakobi, 1981). Centrifugation has also been shown to increase the reac tive oxygen species (ROS) formation in semen, which may affect sperm survival (Shekarriz et al., 1995).

L Carnitine (LC) is a naturally occurring molecule, derived from the amino acid lysine. In cellular systems, LC serves as a facilitator for the transport of activated fatty acids into the mitochondrial matrix, so that they can be broken down through $\beta$ oxidation to produce ATP (Steiber et al., 2004). Very low concentrations of LC have been reported in azoospermic men compared with 
normospermic control (Lewin et al., 1981). Further, lower concentrations of LC were noted in oligoasthenozoosper mic men, and LC supplementation was shown to improve semen quality in these people (Ng et al., 2004). A number of studies have examined the role of $\mathrm{LC}$ in reducing the cellular oxidative stress (Vanella et al., 2000; Apak et al., 2004; Silva Adaya et al., 2008). Studies reported an associ ation between lower levels of LC in semen and male infertility (Matalliotakis et al., 2000; Li et al., 2007). Die tary supplementation with LC has been reported to improve sperm quality (Kozink et al., 2004; Yeste et al., 2009). Further, a positive correlation between free LC in human semen and sperm count and motility has been reported (Menchini Fabris et al., 1984). In addition, it was suggested that LC might be regarded as an index of androgenisation (Abbaticchio et al., 1985). LC showed a protective effect against DNA damage in lymphocytes and brain cerebral cortex of aged rats (Haripriya et al., 2005; Thangasamy et al., 2009). Furthermore, LC was reported to decrease actinomycin $\mathrm{D}$, hydrogen peroxide and TNF alpha induced DNA damage and improve the in vitro blastocyst development rate in mouse embryos (Abdelraz ik et al., 2009).

The main goal of this study was first to standardise the LC doses that are not toxic to spermatozoa and examine LC effectiveness in improving sperm motility and viabil ity, and decreasing sperm DNA oxidation induced by in vitro incubation and centrifugation.

\section{Materials and methods}

\section{Sample collection}

This study was approved by the institutional review board of Cleveland Clinic Hospital. Fifty five normozoospermic men were selected and analysed on the basis of normal semen analysis according to the World Health Organiza tion (1999) guidelines and used to study the effectiveness of LC on sperm motility, viability and sperm DNA oxida tion during incubation and centrifugation. Samples were collected by masturbation following of $4872 \mathrm{~h}$ of sexual abstinence. Following liquefaction at $37^{\circ} \mathrm{C}$ for $20 \mathrm{~min}$, semen specimens were evaluated for volume, sperm con centration, total cell count, motility and morphology. A $5 \mu \mathrm{l}$ aliquot of the sample was used for evaluation of con centration and motility using a microcell slide chamber (Conception Technologies, San Diego, CA, USA).

\section{Effect of various LC concentrations on sperm motility and viability}

Sixteen semen samples were examined. Each sample was divided into six equal aliquots; each contained
$5 \times 10^{6}$ sperm mL ${ }^{1}$. Samples were supplemented with various concentrations of LC dissolved in phosphate buf fered saline (PBS), $\mathrm{pH}$ 7.4. LC concentrations tested were $0.1,0.5,1.0,10$ and $50 \mathrm{mg} \mathrm{ml}{ }^{1}$. The control contained PBS in place of LC. Sperm motility and viability were assessed after 2 and $4 \mathrm{~h}$ incubation at $37^{\circ} \mathrm{C}$.

\section{Measurement of sperm viability}

Sperm viability was measured by eosin nigrosin staining. To one drop of liquefied semen placed on a Boerner slide, two drops of $1 \%$ aqueous eosin were added and mixed with a wooden stirrer for $15 \mathrm{~s}$. Next, three drops of $10 \%$ aqueous nigrosin were added and mixed well. A thin smear was made after pipetting $10 \mu \mathrm{l}$ onto a slide and allowed to air dry. Slides were mounted with a coverslip using Accu mount media. Two hundred spermatozoa on each slide were counted in duplicate using an $\times 100$ objec tive and the percentage of viable (unstained) spermatozoa and nonviable (stained) were calculated.

\section{Effect of LC on sperm motility and viability during centrifugation}

Semen samples $(n=19)$ were divided into two equal aliquots; each aliquot $\left(5 \times 10^{6}\right.$ sperm $)$ was supplemented with $0.5 \mathrm{mg} \mathrm{ml}^{1}$ of LC dissolved in human tubal fluid (HTF); control was supplemented with HTF in the place of LC. Sperm motility and viability were assessed directly after centrifugation at $300 \mathrm{~g}$ for $20 \mathrm{~min}$.

Effect of LC on sperm motility and viability for various sperm concentrations during sperm incubation

Semen samples from 12 donors were used to examine the optimal sperm concentration for studying the effects of LC. Sperm concentrations used were 5, 10, 20 and $40 \times 10^{6} \mathrm{ml}^{1}$. Each aliquot was supplemented with $0.5 \mathrm{mg} \mathrm{ml}^{1}$ LC dissolved in PBS. Control contained PBS in place of LC. Sperm motility and viability were mea sured immediately (time 0 ) and after $2 \mathrm{~h}$ incubation at $37^{\circ} \mathrm{C}$.

\section{Effect of LC on sperm DNA oxidation}

Oxidative damage to DNA was evaluated using the flow cytometric OxiDNA assay kit (Calbiochem, San Diego, CA, USA). The assay is based on utilising a direct fluo rescent protein binding method targeting oxidised sites in DNA. Briefly, sperm samples were treated with LC concentration at 0.5 and $50 \mathrm{mg} \mathrm{ml}{ }^{1}$, incubated for $2 \mathrm{~h}$ at $37^{\circ} \mathrm{C}$, washed twice in PBS, resuspended in $1 \%$ paraformaldehyde at a concentration of 2 
$4 \times 10^{6}$ cell ml $^{1}$ and placed on ice for $1530 \mathrm{~min}$. Spermatozoa were again washed and resuspended in $70 \%$ ice cold ethanol by centrifugation at $300 \mathrm{~g}$ for $5 \mathrm{~min}$ as per the kit instructions. The ethanol superna tant was removed, and the sperm pellets were washed twice in wash buffer and resuspended in $100 \mu$ l of the staining solution for $1 \mathrm{~h}$ at room temperature in dark. The staining solution contained fluorescein isothiocynate (FITC) labelled protein conjugate and distilled water. All cells were further washed using rinse buffer, resus pended in $250 \mu \mathrm{l}$ and incubated for $30 \mathrm{~min}$ in the dark on ice for flow cytometry measurements. Control sam ples without LC supplementation were subjected to the same assay. Negative controls were prepared without FITC staining, while the positive controls were prepared in the presence of $0.5 \mathrm{mM} \mathrm{H}_{2} \mathrm{O}_{2}$ and $0.25 \mathrm{mM} \mathrm{FeSO}_{4}$. To study the effect of LC on sperm DNA oxidation during centrifugation, sperm samples $\left(5 \times 10^{6}\right.$ cell $\left.\mathrm{ml}^{1}\right)$ were treated with one volume HTF supplemented with LC concentration at $0.5 \mathrm{mg} \mathrm{ml}{ }^{1}$, centrifuged for $20 \mathrm{~min}$ at $1600 \mathrm{rpm}$, then submitted to the same treat ment as described earlier.

Data acquisition was performed within $30 \mathrm{~min}$ on a flow cytometer equipped with a $515 \mathrm{~nm}$ argon laser as a light source (FACScan; Becton Dickinson, San Jose, CA, USA). Ten thousand cells were examined for each assay at a flow rate of 100 cells s ${ }^{1}$. The FITC ( $\log$ green fluo rescence) was measured on FL1 channel. Data analysis was performed using FLowJo v4.4.4 software (Tree Star Inc., Ashland, OR, USA).

\section{Statistical analysis}

All values were reported as mean $\pm S D$. Differences were considered significant at $P<0.05$ against control group. Statistical analyses were operated using one way analysis of variance (ANOVA) followed by an unpaired Student's $t$ test.

\section{Results}

Effect of LC on sperm motility and viability on incubation

The effect of various LC concentrations $(0.1,0.5,1.0,10$ and $50 \mathrm{mg} \mathrm{ml}^{1}$ ) on sperm motility and viability was examined after 2 and $4 \mathrm{~h}$ incubation periods at $37^{\circ} \mathrm{C}$ (Fig. 1). Sperm motility was significantly increased after LC supplementation at $0.1,0.5$ and $1.0 \mathrm{mg} \mathrm{ml}^{1}$ after $2 \mathrm{~h}$ incubation $(55.0 \pm 16.9 \%, 58.4 \pm 13.9 \%$ and $52.4 \pm 19 \%$ respectively) compared with the control $(39.4 \pm 15 \%$; $P<0.05$ ) (Fig. la). Semen samples supplemented with LC and evaluated after the $4 \mathrm{~h}$ incubation period did not show any significant increase in sperm motility compared with the control (Fig. 1a). Semen supplementation with LC did not show a statistically significant increase in sperm viability at any concentrations tested compared with the control at both incubation periods (Fig. 1b). LC concentration of $50 \mathrm{mg} \mathrm{ml}{ }^{1}$ significantly reduced sperm motility and viability compared with the control at the two incubation periods $(P<0.05$; Fig. la,b).

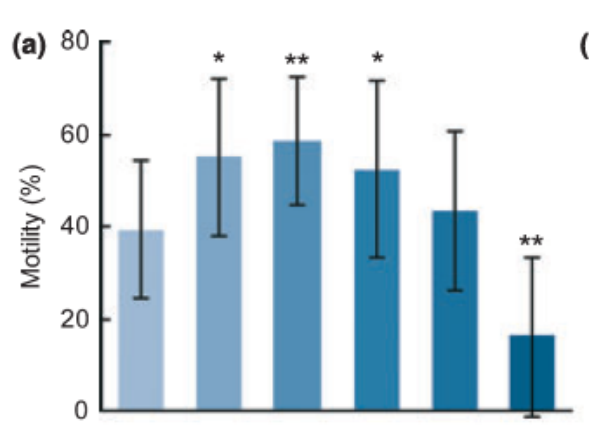

Fig. 1 Effect of various in vitro incubation times with $\mathrm{L}$ carnitine $(\mathrm{LC})$ concentrations at $37^{\circ} \mathrm{C}$ on sperm motility for (a) $2 \mathrm{~h}$ and (b) $4 \mathrm{~h}$; viability (c) $2 \mathrm{~h}$ and (d) $4 \mathrm{~h}$. Data are mean values \pm standard deviations of sperm motility and viability obtained from analysis of sixteen different semen samples. $P$ values for samples and their controls were measured for all LC concentrations ( ${ }^{*} P$ value $<0.05$; $\star \star P$ value $<0.01) ; P<0.05$ was considered statistically significant.

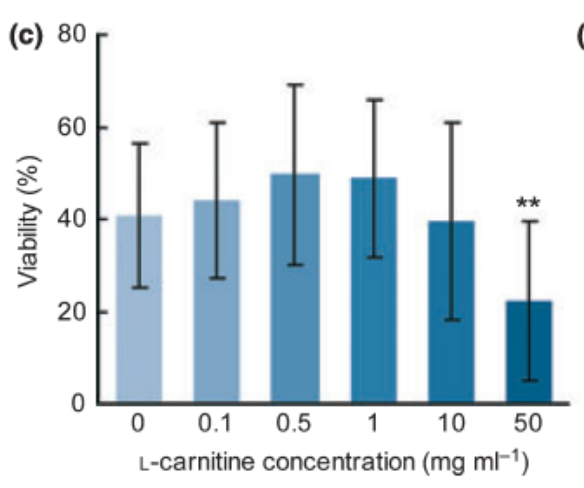

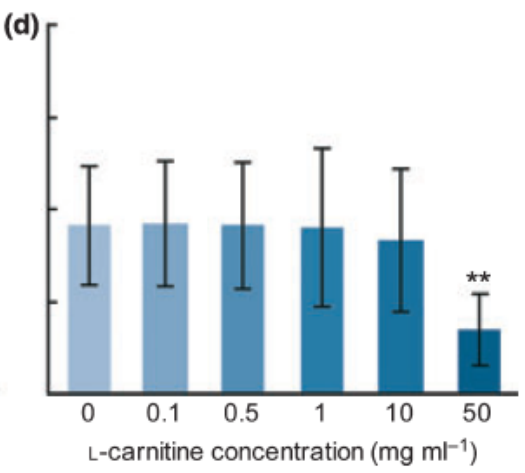


Effect of LC on sperm motility and viability during sperm centrifugation

Figure 2 shows the effect of LC on sperm motility and viability after sperm centrifugation for $20 \mathrm{~min}$ at $1600 \mathrm{rpm}$. Figure $2 \mathrm{a}$ shows the mean values \pm standard deviations of sperm motility for semen samples centri fuged in the presence of LC $\left(0.5 \mathrm{mg} \mathrm{ml}^{\mathbf{1}}\right)$ and samples centrifuged in absence of LC (control). A significant dif ference $(P<0.05)$ in average sperm motility $(37.5 \pm 16.6$ versus $24.0 \pm 12.8 \%$ ) was observed between spermatozoa centrifuged with LC compared with the control. The via bility was comparable between sperm samples treated with LC compared with those without LC treatment $(38.0 \pm 12.0$ versus $34.2 \pm 12.6 \%$ respectively) (Fig. $2 b)$.

Effect of LC on sperm motility and viability for various sperm concentrations

The effect of LC at $0.5 \mathrm{mg} \mathrm{ml}^{1}$ concentration on sperm motility and viability was evaluated for various sperm concentrations $\left(5,10,20\right.$ and 40 million $\left.\mathrm{ml}^{1}\right)$ (Fig. 3). Control samples without LC supplementation were subjected to the same assay conditions. Motility
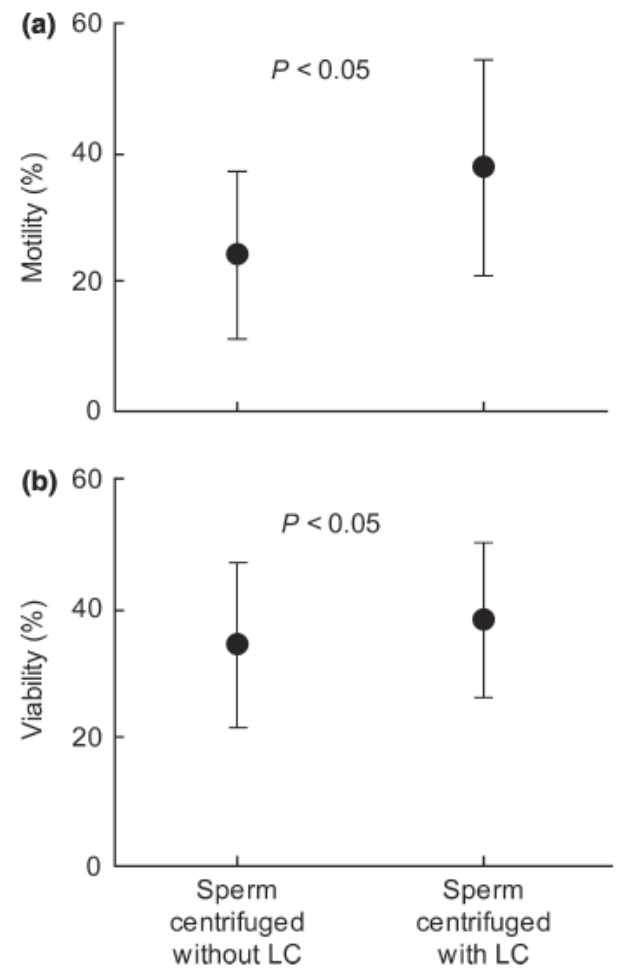

Fig. 2 Effect of centrifugation on (a) sperm motility with and without ( $\mathrm{L}$ carnitine) LC; (b) sperm viability with and without LC. Sperm aliqu ots $(n=19)$ were centrifuged for $20 \mathrm{~min}$ at $300 \mathrm{~g}$. All data are mean values \pm standard deviations. $P<0.05$ are considered statistically sig nificant. and viability of spermatozoa were assessed immediately after $2 \mathrm{~h}$ incubation at $37^{\circ} \mathrm{C}$. A statistically significant increase in sperm motility was observed in semen sam ples supplemented with LC compared with the control only for a sperm concentration of $5 \times 10^{6} \mathrm{ml}^{1}$ $(P<0.05$; Fig. $3 \mathrm{a})$. No increase in sperm viability was seen after addition of LC at all sperm concentrations tested (Fig. 3b).

\section{Effect of LC on sperm DNA oxidation}

The effect of LC on sperm DNA oxidation during incuba tion and centrifugation is shown in Fig. 4. Flow cytome
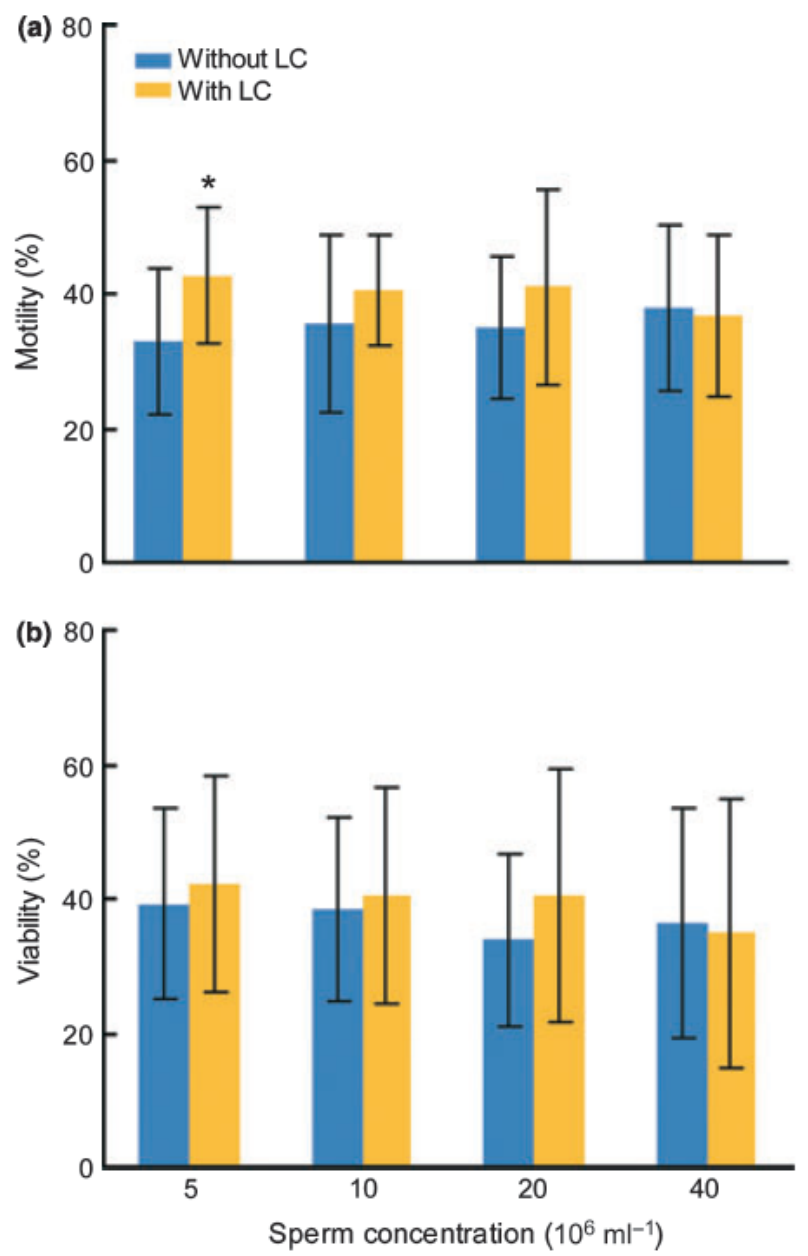

Fig. 3 Effect of L carnitine (LC) $\left(0.5 \mathrm{mg} \mathrm{ml}^{-1}\right)$ on (a) sperm motility and (b) viability following incubation with varying sperm concentra tions (5, 10, 20 and $40 \times 10^{6} \mathrm{ml}^{-1}$ motility and viability of spermato zoa were assessed immediately after $2 \mathrm{~h}$ in vitro incubation at $37^{\circ} \mathrm{C}$. The histograms are mean values \pm standard deviations obtained from analysis of twelve different semen samples (yellow). Controls (blue) were assayed without addition of LC. $P$ values for samples and their controls were measured for all sperm concentrations ( ${ }^{\star} P$ value $<0.05$ ); $P<0.05$ was considered statistically significant. 
try analysis of FITC labelled spermatozoa showed that spermatozoa treated with the LC at 0.5 and $50 \mathrm{mg} \mathrm{ml}^{1}$ for $2 \mathrm{~h}$ at $37^{\circ} \mathrm{C}$ did not increase the intensity of the FITC fluorescence, indicating an insignificant effect on the baseline DNA oxidation (Fig. $4 \mathrm{al}$ a2).

Figure $4 \mathrm{~b}$ shows the effect of LC on the baseline of sperm DNA oxidation during centrifugation as evaluated by flow cytometry. Sperm samples centrifuged with LC at $0.5 \mathrm{mg} \mathrm{ml}{ }^{1}$ concentration did not show a significant dif ference in the intensity of FITC fluorescence, and thus in sperm DNA oxidation, compared with those without LC supplementation.

\section{Discussion}

Studies examining effects of LC on sperm quality in gen eral have focused on the effects of LC in vivo. Recent findings in this context show that administration of LC might antagonise the oxidative as well as the pro inflam matory pathways that attenuate sperm motility (Garolla et al., 2005; Abd Allah et al., 2009; Yeste et al., 2009). In the present study, we have focused on the role of LC in improving sperm quality in vitro. In the first series of experiments, we standardised the LC concentrations, util ising semen from normozoospermic donors and estab lished that $0.1,0.5$ and $1.0 \mathrm{mg} \mathrm{ml}{ }^{1}$ concentrations were not toxic.

To study the effect of LC on sperm motility and viabil ity during sperm centrifugation, we used LC at a concen tration of $0.5 \mathrm{mg} \mathrm{ml}^{1}$. Sperm aliquots with and without LC (control) were centrifuged for $20 \mathrm{~min}$ at $300 \mathrm{~g}$, sperm motility and viability were assessed. Our results suggest that LC at the standardised concentrations was beneficial and improved sperm motility, in particular, after the $2 \mathrm{~h}$ incubation period. A significant increase in sperm motil ity was observed in the centrifuged spermatozoa supple mented with LC compared with the control. Similar enhancement in sperm motility in vitro has been reported after adding acetylcarnitine, an acetylated form of carni tine, to semen at $37^{\circ} \mathrm{C}$ (Tanphaichitr, 1977). This posi tive effect of LC on sperm motility is due to its role in sperm metabolism as well as its antioxidant properties (Agarwal \& Said, 2004; Gulcin, 2006). LC facilitates the transport of long chain fatty acids across the inner mem brane of mitochondria, so that they can be broken down through $\beta$ oxidation to produce ATP (Steiber et al., 2004); therefore, providing readily available energy for use by spermatozoa. Accumulation of the ROS in sperma tozoa leads to ATP depletion, lipid peroxidation and insufficient axonemal phosphorylation (Dokmeci, 2005). The property of LC as a scavenger for ROS could thus be responsible for its positive effect on sperm motility. This is in agreement with a study by Balercia et al. (2005),
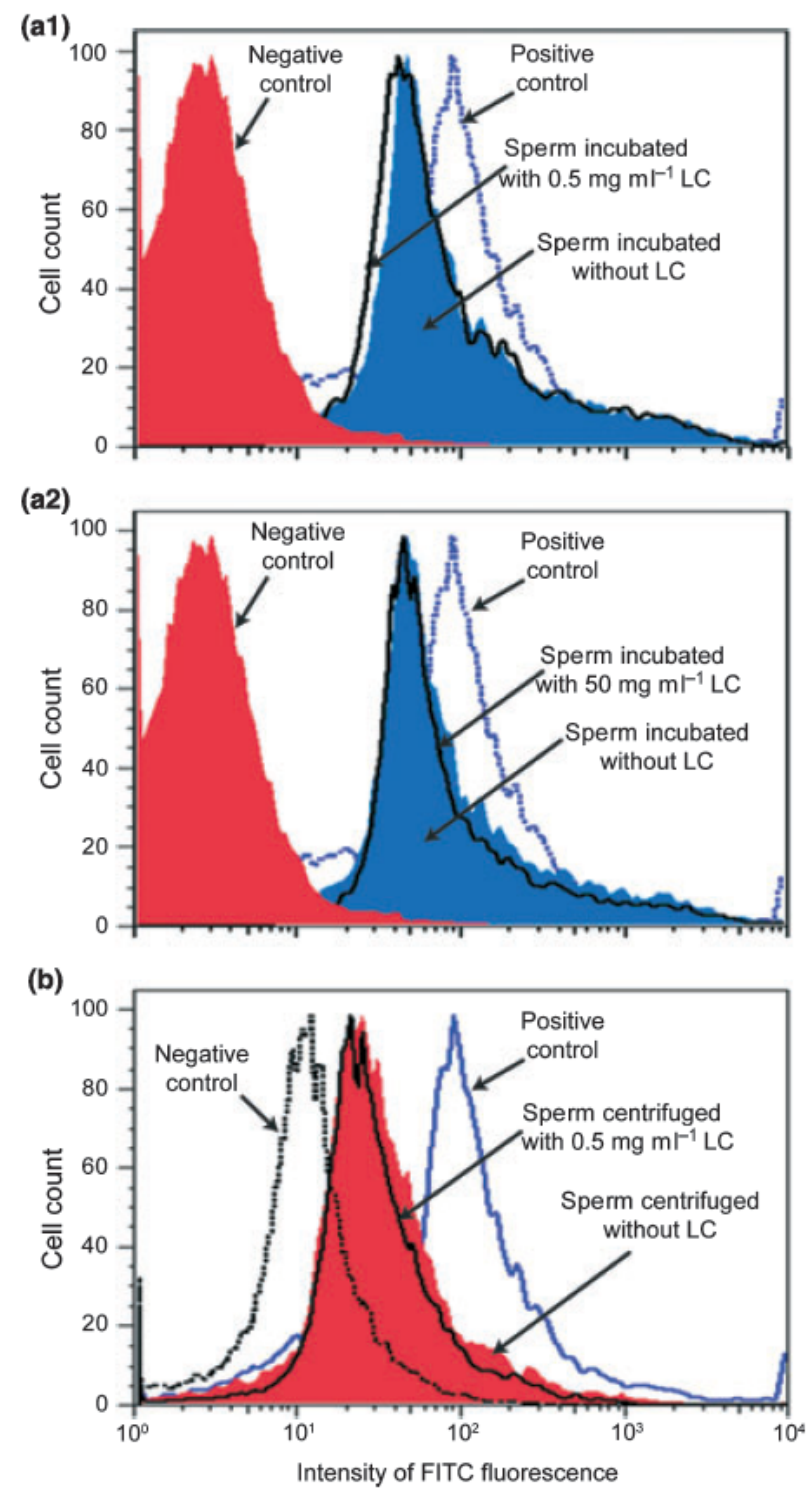

Fig. 4 Effect of L carnitine (LC) on sperm DNA oxidation during sperm incubation and centrifugation and evaluated by flow cytometry. (a1) Spermatozoa incubated for $2 \mathrm{~h}$ with $0.5 \mathrm{mg} \mathrm{ml}^{-1}$ and (a2) $50 \mathrm{mg} \mathrm{ml}^{-1} \mathrm{LC}$ concentrations at $37^{\circ} \mathrm{C}$. (b) Spermatozoa centrifuged in the presence of $0.5 \mathrm{mg} \mathrm{ml}^{-1} \mathrm{LC}$ for $20 \mathrm{~min}$ at $300 \mathrm{~g}$. Sample con trols assayed in the absence of LC in both incubation and centrifuga tion. Negative controls were analysed without FITC staining; positive controls contained $\mathrm{H}_{2} \mathrm{O}_{2}$ induced sperm DNA oxidative damage. The $X$ axis represents the intensity of sperm labelled FITC fluorescence. Data are representative of four independent experiments.

who showed that LC and acetylcarnitine administration in vivo increased total seminal antioxidant activity as well as sperm motility in idiopathic asthenozoospermic patients.

L Carnitine contributes in shielding sperm membranes against harmful ROS because of its antioxidant activity 
(Gulcin, 2006). It also decreases the availability of lipids for peroxidation via easing the transport of fatty acids to the mitochondrial matrix for $\beta$ oxidation (Thangavel \& Panneerselvama, 1998). Neuman et al. (2002) reported that dietary supplementation with LC reduces sperm lipid peroxidation in roosters; this may preserve sperm mem branes, thereby increasing their viability (Neuman et al., 2002). We therefore anticipated that in vitro incubation of semen samples with LC would improve sperm viability. Contrary to our expectation, we observed that semen sup plementation with LC showed only a slight but statisti cally insignificant effect in improving sperm viability during incubation. Similar insignificant effects were reported earlier by Duru et al. (2000), who studied the influence of acetyl $\mathrm{L}$ carnitine on sperm membrane dam age after cryopreservation thawing cycles. Similarly, using in vivo systems, it was found that dietary supplementation with LC did not improve the membrane integrity of pony stallion spermatozoa (Deichsel et al., 2008). A more recent study by Yeste et al. (2009) showed that the addi tion of LC to the boar's diet had no effect on their sperm viability. In contrast, LC administration to infertile human men with poor sperm motility $(<50 \%)$ was effec tive in improving membrane integrity of the ejaculated spermatozoa (De Rosa et al. (2005). In our in vitro study, we only added LC to semen samples with normal motility $(>50 \%)$. A similar in vitro study utilising semen samples from infertile subjects is needed to assess LC effect on sperm viability during incubation and substantiate our findings.

Furthermore, Duru et al. (2000) used two assays; eosin $\mathrm{Y}$ staining and annexin $\mathrm{V}$ Cy3 in their study to measure sperm viability after cryopreservation thawing. These investigators observed significant discrepancy between the percentages of spermatozoa marked as 'live' between eosin Y staining and annexin V Cy3 assay. The eosin staining showed a lower percentage of viable sper matozoa compared with the annexin V Cy3 assay. These investigators attributed this discrepancy to the different mechanisms through which these assays operate. In our study, we measured sperm viability using the eosin stain ing assay, which is based on the membrane permeability for the eosin stain. Therefore, the mechanism by which this assay recognises live spermatozoa could be a contrib uting factor in this insignificant effect of LC on sperm viability.

The influence of LC on sperm motility and viability of various sperm concentrations was also investigated (Fig. 3). We supplemented different concentrations of spermatozoa with LC at $0.5 \mathrm{mg} \mathrm{ml}{ }^{1}$. Our results from this experiment suggest that LC was effective in increasing sperm motility only when utilising sperm concentration of $5 \times 10^{6}$ cell ml ${ }^{1}$. At higher sperm concentrations, the decrease in the ratio of the sperm number against avail able LC molecules may explain the lack of effect in improving the sperm motility. On the other hand, sperm viability did not increase utilising any of the sperm con centrations. These results are in agreement with our experiment earlier. This information may be exploited in exploring and designing protocols that aim to improve sperm motility in patients with low sperm count, espe cially oligozoospermic men.

L Carnitine has been shown to improve resistance to oxidative stress by decreasing DNA damage in Ataxia tel angiectasia cells (Berni et al., 2008). Moreover, Thangas amy et al. (2009) reported that LC significantly reduces DNA damage in lymphocytes of aged rats. We also recently demonstrated the effectiveness of LC in reducing $\mathrm{H}_{2} \mathrm{O}_{2}$ induced DNA damage and improvement of in vitro blastocyst development rate in mouse embryos (Abdelraz ik et al., 2009). In the present study, we examined whether LC had similar effects on human sperm DNA in vitro. We incubated the sperm samples with the stan dardised LC concentration $0.5 \mathrm{mg} \mathrm{ml}{ }^{1}$, at $37{ }^{\circ} \mathrm{C}$ for $2 \mathrm{~h}$. We did not see the decrease in the extent of the sperm DNA oxidation (Fig. 4a1). Similarly, we did not see a sig nificant effect of LC on the baseline of sperm DNA oxida tion after centrifugation compared with control samples (i.e. centrifugation without LC) (Fig. 4b).

Studies in vitro show that semen supplementation with an antioxidant does not affect sperm DNA integrity. In fact, Donnelly et al. (1999a) showed that neither addition of ascorbate nor addition of $\alpha$ tocopherol to sperm prep aration medium affected baseline DNA integrity of sper matozoa. However, both antioxidants provided protection against the $\mathrm{H}_{2} \mathrm{O}_{2}$ induced DNA damage in spermatozoa (Donnelly et al., 1999b). Similar reports showed that addition of vitamin $\mathrm{E}$ to cryopreservation medium did not alter the post thaw DNA fragmentation of spermato zoa (Taylor et al., 2009). These results are in line with our observations, which do not show a significant effect of LC as an antioxidant in reducing DNA oxidative dam age in spermtozoa.

One explanation for the undetectable effect of LC on sperm DNA oxidation may be the fact that we used only semen samples from normozoospermic subjects in our study. In the present study, we measured the effect of LC on DNA oxidation in spermatozoa induced only by in vitro incubation and centrifugation, but not by exoge nous induction of oxidative damage. This might be another likely reason for the lack of a significant effect of LC on sperm DNA oxidation as reported by others (Donnelly et al., 1999b; Berni et al., 2008; Abd Allah et al., 2009; Abdelrazik et al., 2009).

Another reason for lack of improvement in DNA oxi dation may be the fact that mammalian sperm DNA is 
highly compacted (6 fold more highly condensed) com pared with DNA in somatic cells (Ward \& Coffey, 1991). Also, the majority of antioxidants in somatic cells are present within their cytoplasm, while in spermato zoa, a significant amount of the antioxidants are present in seminal plasma outside the spermatozoa, because spermatozoa lose most of its cytoplasm during matura tion (Donnelly et al., 1999a). Therefore, the differences in the DNA packaging and the distribution of antioxi dants between spermatozoa and somatic cells might introduce variations in outcomes when measuring the effect of in vitro supplementation of antioxidants on DNA oxidation.

It has been shown that cell treatment with high con centrations of antioxidants in vitro increases the levels of 8 oxoguanine moieties on DNA, a biomarker for DNA oxidative damage (Gutteridge, 1994). Increasing DNA oxidative damage may lead to apoptosis and cell death (Wang et al., 2003; Hurh et al., 2004. We therefore exam ined whether high LC concentration decreased in vitro sperm quality by inducing sperm DNA oxidation. We measured the 8 oxoguanine moieties in the sperm DNA after incubating the spermatozoa with $50 \mathrm{mg} \mathrm{ml}^{1} \mathrm{LC}$ using flow cytometry. Our results suggest that this might not be the likely mechanism by which the high LC level negatively affects sperm quality in vitro (Fig. 4a2). Again the fact that all samples from normozoospermic subjects may also explain the lack of any significant effects of LC on DNA damage.

In conclusion, LC enhances sperm motility following in vitro incubation and centrifugation, while it might not significantly affect sperm viability and baseline DNA oxi dation of spermatozoa. These results provide a solid foundation to explore and design protocols to test the potentially beneficial effect of LC supplementation for the spermatozoa prepared for ART.

\section{References}

Abbaticchio G, Giagulli VA, Defini M, Micale FM, Giorgino R (1985) Free L carnitine in human semen. Arch Androl 15:137 142 .

Abd Allah AR, Helal GK, Al Yahya AA, Aleisa AM, Al Rejaie SS, Al Bakheet SA (2009) Pro inflammatory and oxidative stress pathways which compromise sperm motility and survival may be altered by 1 carnitine. Oxid Med Cell Longev 2:73 81 .

Abdelrazik H, Sharma R, Mahfouz R, Agarwal A (2009)

$\mathrm{L}$ carnitine decreases DNA damage and improves the in vitro blastocyst development rate in mouse embryos. Fertil Steril 91:589 596.

Agarwal A, Said TM (2004) Carnitines and male infertility. Reprod Biomed Online 8:376 384.
Apak R, Guclu K, Ozyurek M, Karademir SE (2004) Novel total antioxidant capacity index for dietary polyphenols and vitamins $\mathrm{C}$ and $\mathrm{E}$, using their cupric ion reducing capability in the presence of neocuproine: Cuprac method.

J Agric Food Chem 52:7970 7981.

Balercia G, Regoli F, Armeni T, Koverech A, Mantero F, Boscaro M (2005) Placebo controlled double blind randomized trial on the use of $\mathrm{L}$ carnitine, $\mathrm{L}$ acetylcarnitine, or combined L carnitine and L acetylcarnitine in men with idiopathic asthenozoospermia. Fertil Steril 84:662 671.

Berni A, Meschini R, Filippi S, Palitti F, De Amicis A, Chessa L (2008) L carnitine enhances resistance to oxidative stress by reducing DNA damage in ataxia telangiectasia cells. Mutat Res 650:165 174.

Brugh VM III, Lipshultz LI (2004) Male factor infertility: evaluation and management. Med Clin North Am 88:367 385 .

De Rosa M, Boggia B, Amalfi B, Zarrilli S, Vita A, Colao A, Lombardi G (2005) Correlation between seminal carnitine and functional spermatozoal characteristics in men with semen dysfunction of various origins. Drugs $R$ D 6:1 9 .

Deichsel K, Palm F, Koblischke P, Budik S, Aurich C (2008) Effect of a dietary antioxidant supplementation on semen quality in pony stallions. Theriogenology 69:940 945 .

Dokmeci D (2005) Oxidative stress, male infertility and the role of carnitines. Folia Med (Plovdiv) 47:26 30.

Donnelly ET, McClure N, Lewis SE (1999a) The effect of ascorbate and alpha tocopherol supplementation in vitro on DNA integrity and hydrogen peroxide induced DNA damage in human spermatozoa. Mutagenesis 14:505 512.

Donnelly ET, McClure N, Lewis SE (1999b) Antioxidant supplementation in vitro does not improve human sperm motility. Fertil Steril 72:484 495.

Duru NK, Morshedi M, Schuffner A, Oehninger S (2000) Semen treatment with progesterone and/or acetyl 1 carnitine does not improve sperm motility or membrane damage after cryopreservation thawing. Fertil Steril 74:715 720.

Garolla A, Maiorino M, Roverato A, Roveri A, Ursini F, Foresta C (2005) Oral carnitine supplementation increases sperm motility in asthenozoospermic men with normal sperm phospholipid hydroperoxide glutathione peroxidase levels. Fertil Steril 83:355 361.

Gulcin I (2006) Antioxidant and antiradical activities of 1 carnitine. Life Sci 78:803 811.

Gutteridge JM (1994) Antioxidants, nutritional supplements and life threatening diseases. Br J Biomed Sci 51:288 295.

Haripriya D, Sangeetha P, Kanchana A, Balu M, Panneerselvam C (2005) Modulation of age associated oxidative DNA damage in rat brain cerebral cortex, striatum and hippocampus by 1 carnitine. Exp Gerontol 40:129 135.

Hurh YJ, Chen ZH, Na HK, Han SY, Surh YJ (2004)

2 hydroxyestradiol induces oxidative DNA damage and apoptosis in human mammary epithelial cells. J Toxicol Environ Health A 67:1939 1953. 
Jeulin C, Serres C, Jouannet P (1982) The effects of centrifugation, various synthetic media and temperature on the motility and vitality of human spermatozoa.

Reprod Nutr Dev 22:81 91.

Kozink DM, Estienne MJ, Harper AF, Knight JW (2004) Effects of dietary 1 carnitine supplementation on semen characteristics in boars. Theriogenology 61:1247 1258 .

Lamb DJ, Lipshultz LI (2000) Male infertility: recent advances and a look towards the future. Curr Opin Urol 10:359 362.

Lewin LM, Shalev DP, Weissenberg R, Soffer Y (1981) Carnitine and acylcarnitines in semen from azoospermic patients. Fertil Steril 36:214 218.

Li K, Li W, Huang YF, Shang XJ (2007) Level of free 1 carnitine in human seminal plasma and its correlation with semen quality. Zhonghua Nan Ke Xue 13:143 146.

Makler A, Jakobi P (1981) Effects of shaking and centrifugation on human sperm motility. Arch Androl 7: 2126.

Matalliotakis I, Koumantaki Y, Evageliou A, Matalliotakis G, Goumenou A, Koumantakis E (2000) L carnitine levels in the seminal plasma of fertile and infertile men: correlation with sperm quality. Int J Fertil Womens Med 45:236 240.

Matas C, Decuadro G, Martinez Miro S, Gadea J (2007) Evaluation of a cushioned method for centrifugation and processing for freezing boar semen. Theriogenology 67: 10871091.

Menchini Fabris GF, Canale D, Izzo PL, Olivieri L, Bartelloni M (1984) Free l carnitine in human semen: its variability in different andrologic pathologies. Fertil Steril 42:263 267.

Neuman SL, Lin TL, Heste PY (2002) The effect of dietary carnitine on semen traits of white leghorn roosters. Poult Sci 81:495 503.

Ng CM, Blackman MR, Wang C, Swerdloff RS (2004) The role of carnitine in the male reproductive system. Ann N Y Acad Sci 1033:177 188.

Shekarriz M, DeWire DM, Thomas AJ Jr, Agarwal A (1995) A method of human semen centrifugation to minimize the iatrogenic sperm injuries caused by reactive oxygen species. Eur Urol 28:31 35.

Silva Adaya D, Perez De Cruz La V, Herrera Mundo MN, Mendoza Macedo K, Villeda Hernandez J, Binienda Z, Ali SF, Santamaria A (2008) Excitotoxic damage, disrupted energy metabolism, and oxidative stress in the rat brain: antioxidant and neuroprotective effects of 1 carnitine. J Neurochem 105:677 689.

Singer R, Sagiv M, Landau B, Allalouf D, Segenreich E, Servadio C (1980) Motility and vitality of human spermatozoa at various time intervals after ejaculation. Experientia 36:578 579.

Steiber A, Kerner J, Hoppel CL (2004) Carnitine: a nutritional, biosynthetic, and functional perspective. Mol Aspects Med 25:455 473.

Tanphaichitr N (1977) In vitro stimulation of human sperm motility by acetylcarnitine. Int J Fertil 22:85 91.

Taylor K, Roberts P, Sanders K, Burton P (2009) Effect of antioxidant supplementation of cryopreservation medium on post thaw integrity of human spermatozoa. Reprod Biomed Online 18:184 189.

Thangasamy T, Jeyakumar P, Sittadjody S, Joyee AG, Chinnakannu P (2009) L carnitine mediates protection against DNA damage in lymphocytes of aged rats. Biogerontology 10:163 172.

Thangavel K, Panneerselvama C (1998) Effect of L carnitine on the status of lipid peroxidation and antioxidants in aging rats. J Nutr Biochem 9:575 581.

Vanella A, Russo A, Acquaviva R, Campisi A, Di Giacomo C, Sorrenti V, Barcellona ML (2000) L propionyl carnitine as superoxide scavenger, antioxidant, and DNA cleavage protector. Cell Biol Toxicol 16:99 104.

Wang X, Sharma RK, Sikka SC, Thomas AJ Jr, Falcone T, Agarwal A (2003) Oxidative stress is associated with increased apoptosis leading to spermatozoa DNA damage in patients with male factor infertility. Fertil Steril 80:531 535.

Ward WS, Coffey DS (1991) DNA packaging and organization in mammalian spermatozoa: comparison with somatic cells. Biol Reprod 44:569 574.

World Health Organization (1999) Laboratory Manual for the Examination of Human Semen and Sperm Cervical Mucus Interaction, 4th edn. Cambridge University Press, Cambridge.

Yeste M, Sancho S, Briz M, Pinart E, Bussalleu E, Bonet S (2009) A diet supplemented with L carnitine improves the sperm quality of pietrain but not of duroc and large white boars when photoperiod and temperature increase. Theriogenology 73:577 586. 